\title{
NEW CHEMISTRY OF METALLOCARBORANES AND METALLOBORANES*
}

\author{
Kenneth P. Callahan and M. Frederick Hawthorne \\ Department of Chemistry, University of California, Los Angeles, \\ California 90024, USA
}

\begin{abstract}
Ten years after the discovery of metallocarboranes, this field of chemistry is still advancing at a rapid pace. While the polyhedral expansion of carboranes has proved to be a general method for the synthesis of metallocarboranes, polymetallic compounds may be synthesized by polyhedral expansion of monometallocarboranes, sometimes producing supraicosahedral complexes. The polyhedral contraction reaction, which produces lower metallocarborane compounds, may be used in conjunction with expansion techniques to regulate polyhedral size. Polyhedral subrogation allows the replacement of a polyhedral $\{\mathrm{BH}\}$ vertex with a transition metal, and therefore complements the other two new synthetic tools. The synthesis of metallocarboranes by thermal metal transfer, while still in its early stages of development, may prove to be another valuable synthetic method. Recent studies on the chemistry of certain metallocarboranes have shown oxidative addition to a polyhedral $\{\mathrm{BH}\}$ vertex. In addition, specific catalytic hydrogen-deuterium exchange on boron hydrides, carboranes and metallocarboranes occurs with several transition metal complexes. A new rhodium metallocarborane has been shown to be an excellent catalyst for olefin hydrogenation, hydrogen-deuterium exchange on boron, olefin isomerization and hydrosilylation.
\end{abstract}

\section{HISTORICAL PERSPECTIVE}

This year marks the tenth anniversary of the welding of two diverse areas of chemistry, those of the transition metals and of the boron hydrides, by the discovery of the first metallocarborane complex ${ }^{1}$. The rationale behind this combination of diverse specialities was developed from two major chemical advances: the synthesis ${ }^{2}$ and the molecular orbital description ${ }^{3}$ of ferrocene and the discovery ${ }^{4}$ of the degradation of icosahedral carboranes to produce anionic species. The realization that these carborane anions, when fully deprotonated to form $\mathrm{C}_{2} \mathrm{~B}_{9} \mathrm{H}_{11}^{2-}$ dianions, should have orbitals of proper symmetry and energy to interact with transition metals, as was found with the cyclopentadienide ion, led to the synthesis of the carborane analogue of ferrocene, the bis(dicarbollyl)iron(II) dianion, $\left[\left(1,2-\mathrm{C}_{2} \mathrm{~B}_{9} \mathrm{H}_{11}\right)_{2}\right.$ $\mathrm{Fe}]^{2-1}$.

*Contribution No. 3321 from the Department of Chemistry, University of California, Los Angeles, California 90024. 


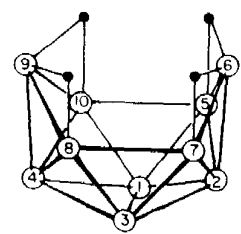

$\mathrm{B}_{10} \mathrm{H}_{14}$

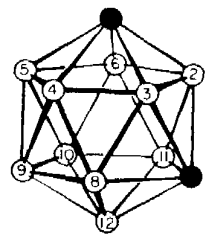

$1,7 \cdot \mathrm{C}_{2} \mathrm{~B}_{10} \mathrm{H}_{12}$
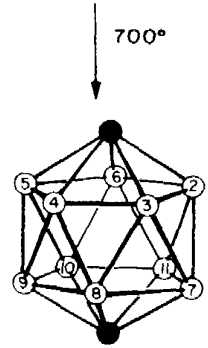

$1,12-\mathrm{C}_{2} \mathrm{~B}_{10} \mathrm{H}_{12}$

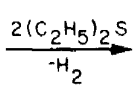

$600^{\circ}$

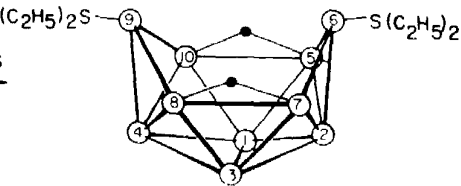

$$
\mathrm{B}_{10} \mathrm{H}_{12}\left[\mathrm{~S}\left(\mathrm{C}_{2} \mathrm{H}_{5}\right)_{2}\right]_{2}
$$
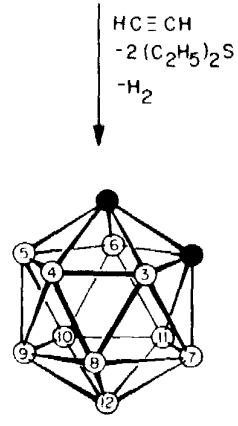

$1,2-\mathrm{C}_{2} \mathrm{~B}_{10} \mathrm{H}_{12}$

$\mathrm{KOH}$ $\mathrm{C}_{2} \mathrm{H}_{5} \mathrm{OH}$

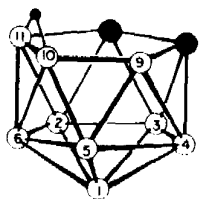

$7,8-\mathrm{C}_{2} \mathrm{~B}_{9} \mathrm{H}_{12}-$

Figure 1. Preparation of $\mathrm{C}_{2} \mathrm{~B}_{10} \mathrm{H}_{12}$ isomers from decaborane, $\mathrm{B}_{10} \mathrm{H}_{14}$. The degradation of the carborane cage to $\mathrm{C}_{2} \mathrm{~B}_{9} \mathrm{H}_{12}$ ions is also shown. Filled circles, $\mathrm{CH}$; open circles, $\mathrm{BH}$.

The synthetic pathway necessary to produce the carborane ligand is shown in Figure 1, which indicates the production of the isomeric $\mathrm{C}_{2} \mathrm{~B}_{10} \mathrm{H}_{12}$ icosahedra from their parent boron hydride, decaborane, $\mathrm{B}_{10} \mathrm{H}_{14}$. The similarity of the molecular orbitals calculated ${ }^{3}$ for $\mathrm{C}_{5} \mathrm{H}_{5}^{-}$in ferrocene, and those believed ${ }^{5}$ to exist in the $\mathrm{C}_{2} \mathrm{~B}_{9} \mathrm{H}_{11}^{2-}$ (dicarbollide) ligand is shown schematically in Figure 2, and the structure of the first-reported metallocarborane complex is presented in Figure 3.

Subsequent to the preparation of the first metallocarborane, 'mixed' sandwich complexes involving both dicarbollide $\left(\mathrm{C}_{2} \mathrm{~B}_{9} \mathrm{H}_{11}^{2-}\right)$ and carbonyl or cyclopentadienyl ligands were synthesized ${ }^{6,7}$, and complexes of several 

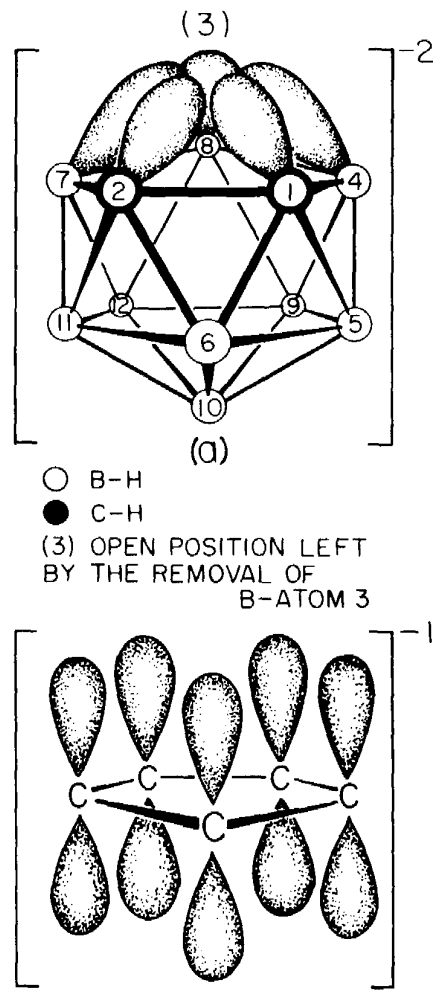

(b)

Figure 2. Schematic representation of the $s p^{3}$-like bonding orbitals in $\mathrm{C}_{2} \mathrm{~B}_{9} \mathrm{H}_{11}^{2-}$ (a) compared to the $p$ bonding orbitals of $\mathrm{C}_{5} \mathrm{H}_{5}^{--}$(b).

other transition metals, including manganese, rhenium $^{6}$, cobalt $^{8}$, palladium $^{9}$, nickel $^{10}$, copper, molybdenum and tungsten ${ }^{11}$ were reported. Complexes of lower carboranes were also synthesized in a similar manner ${ }^{12,13}$. The properties of the metallocarboranes thus prepared indicated that there were important differences between these species and their bis(cyclopentadienyl) analogues, most notably in their stabilities and in their electronic properties. For example, bis(dicarbollyl) copper(II) and (III) complexes have been well-characterized ${ }^{11,14}$, yet cuprocene, $\left(\mathrm{C}_{5} \mathrm{H}_{5}\right)_{2} \mathrm{Cu}$, is unknown. The preferred oxidation state of the iron atom in ferrocene is dipositive, the ferricinium ion being rather reactive, yet bis(dicarbollyl)iron(II) is quantitatively air-oxidized to the extremely stable $\mathrm{Fe}(\mathrm{III})$ complex. Even more surprising is the existence of the bis(dicarbollyl)nickel(Iv) species; the corresponding bis(cyclopentadienyl)nickel(Iv) dication is only observable electrochemically at $-40^{\circ 15}$.

The properties of metallocarboranes mentioned above, as well as their high thermal and oxidative stabilities, have prompted us to engage in a 


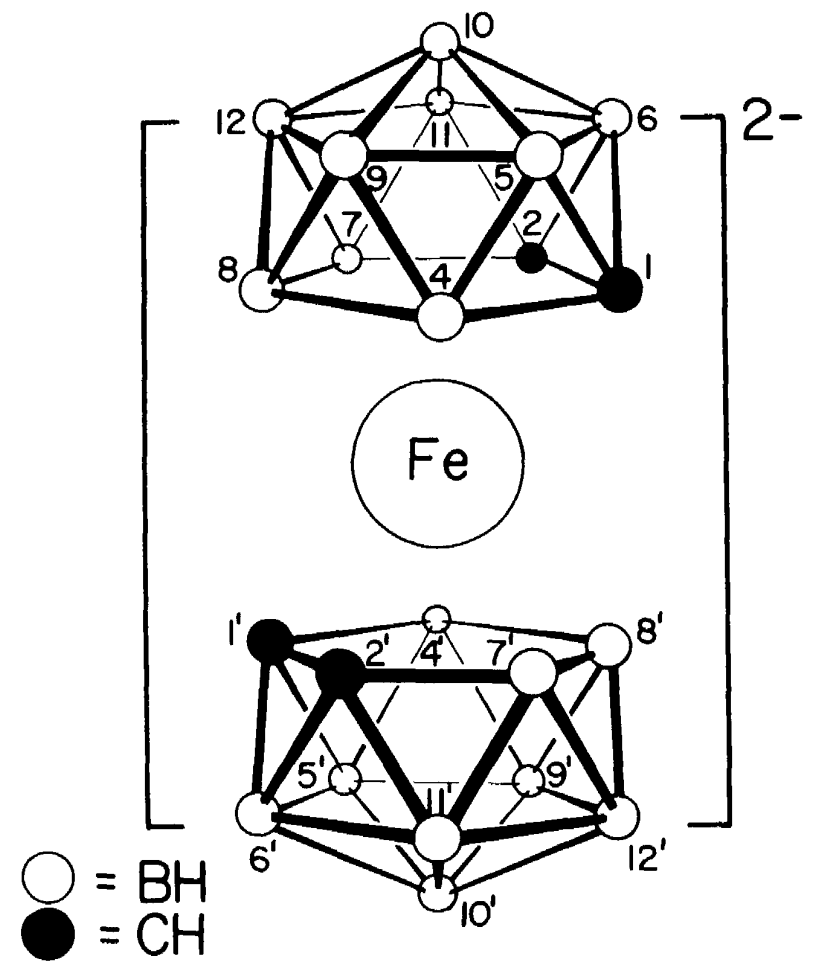

Figure 3. Structure of the first metallocarborane synthesized $\left[\left(1,2-\mathrm{C}_{2} \mathrm{~B}_{4} \mathrm{H}_{1,1}\right)_{2}-\mathrm{Fe}(\mathrm{II})\right]^{2}$.

comprehensive study of these unique molecules. Much of this work has been in synthetic chemistry, involving new approaches to metallocarboranes and the reactions of these compounds. Thermal polyhedral rearrangement has been shown to be possible in metallocarboranes as well as carboranes, and some rearrangements have been found to proceed at surprisingly moderate temperatures. Recent work in our laboratories has involved the catalytic properties of some metallocarboranes, and will conclude this survey of our recent investigations.

\section{ADVANCES IN METALLOCARBORANE SYNTHESIS}

\section{(A) Polyhedral expansion of carboranes}

An alternative route to metallocarboranes which does not involve degradation of a carborane prior to complexation with a transition metal has been developed over the past several years. This reaction appears to be general for carboranes, and has been termed 'polyhedral expansion', for it formally involves the addition of a new, metallic vertex to the vertices of the carborane starting material. 
The strategic concept of this new synthetic method is based upon the assumed similarity of the 'aromaticity' of benzenoid hydrocarbons and $\mathrm{B}_{n} \mathrm{C}_{2} \mathrm{H}_{n+2}$ carboranes. The former species accept electrons into their nonbonding and lowest energy antibonding molecular orbitals upon chemical reduction, and it was thought that a similar process in the carboranes could produce geometrical changes and orbital populations favourable to metallocarborane formation.

The two-electron reduction of the 8-vertex closed polyhedral compound $1,7-\mathrm{C}_{2} \mathrm{~B}_{6} \mathrm{H}_{8}$ was readily accomplished ${ }^{16}$ with sodium naphthalide in tetrahydrofuran (THF) solution; reaction of the resulting carborane dianion with excess sodium cyclopentadienide and cobaltous chloride afforded two products, the monometallic $\mathrm{C}_{5} \mathrm{H}_{5} \mathrm{CoC}_{2} \mathrm{~B}_{6} \mathrm{H}_{8}$, and a complex with two metal atoms incorporated in the polyhedron, formulated as $\left(\mathrm{C}_{5} \mathrm{H}_{5}\right)_{2} \mathrm{Co}_{2} \mathrm{C}_{2} \mathrm{~B}_{6} \mathrm{H}_{8}$. This reaction sequence is shown in Figure 4. The monometallic product,

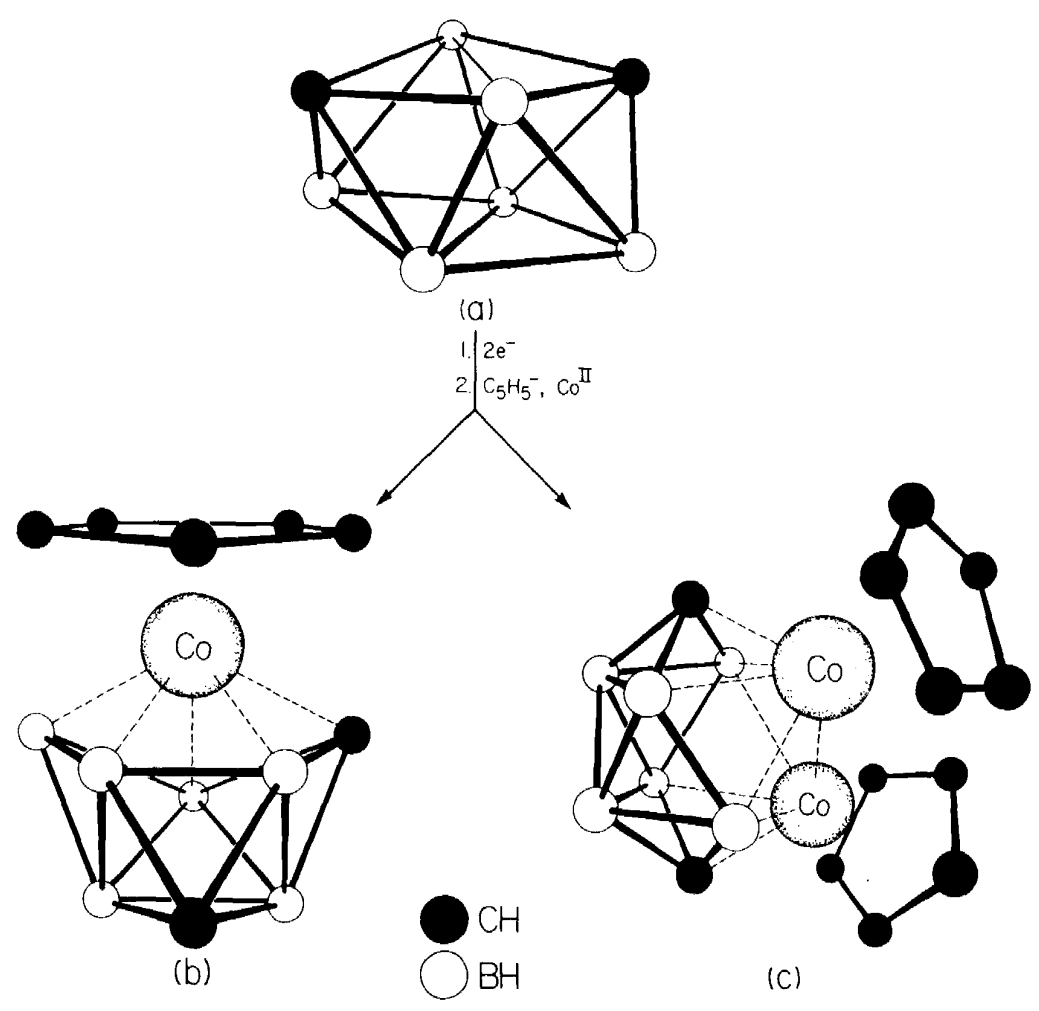

Figure 4. Polyhedral expansion of $1,7-\mathrm{C}_{2} \mathrm{~B}_{6} \mathrm{H}_{8}$.

a 9-vertex polyhedron, has one vertex more than the starting material and exemplifies the polyhedral expansion process. The second product is apparently the result of double polyhedral expansion, a 10-vertex bimetallic 
complex. The structure of this species has recently been determined by $x$-ray crystallography ${ }^{17}$ and found to contain a metal-metal bond, the two cobalt vertices being separated by only $2.49 \AA$. These products indicated that the polyhedral expansion method was indeed capable of producing new metallocarboranes in which the size of the polyhedron was increased by one, or even by two vertices, depending on how many metal atoms were incorporated. The production of a bimetallic complex also heralded the possibility that a metallocarborane could undergo polyhedral expansion, thereby affording routes to bi-, tri- and even higher polymetallocarboranes.

Polyhedral expansion was attempted on carboranes other than $\mathrm{C}_{2} \mathrm{~B}_{6} \mathrm{H}_{8}$, both to test the generality of the reaction sequence as the number of polyhedral vertices in the starting material increased, and to determine what types of products would be produced under these conditions as the geometry of the starting material was altered. The polyhedral expansion of 4,5$\mathrm{C}_{2} \mathrm{~B}_{7} \mathrm{H}_{9}{ }^{18}$, depicted in Figure 5. was unusual in several respects. Three major products were isolated; one was the expected polyhedral expansion product, a 10-vertex cobaltacarborane having the formula $\mathrm{C}_{5} \mathrm{H}_{5} \mathrm{CoC}_{2} \mathrm{~B}_{7} \mathrm{H}_{9}$, which spectral studies proved to be a new isomer of the complexes previously synthesized by proton abstraction from $6,8-\mathrm{C}_{2} \mathrm{~B}_{7} \mathrm{H}_{13}{ }^{12}$. The other two products formed in this reaction were formulated as $\mathrm{C}_{5} \mathrm{H}_{5} \mathrm{CoC}_{2} \mathrm{~B}_{6} \mathrm{H}_{8}$ and $\left(\mathrm{C}_{5} \mathrm{H}_{5}\right)_{2} \mathrm{Co}_{2} \mathrm{C}_{2} \mathrm{~B}_{8} \mathrm{H}_{10}$, and indicated that chemistry other than simple polyhedral expansion had occurred in this reaction. The former compound
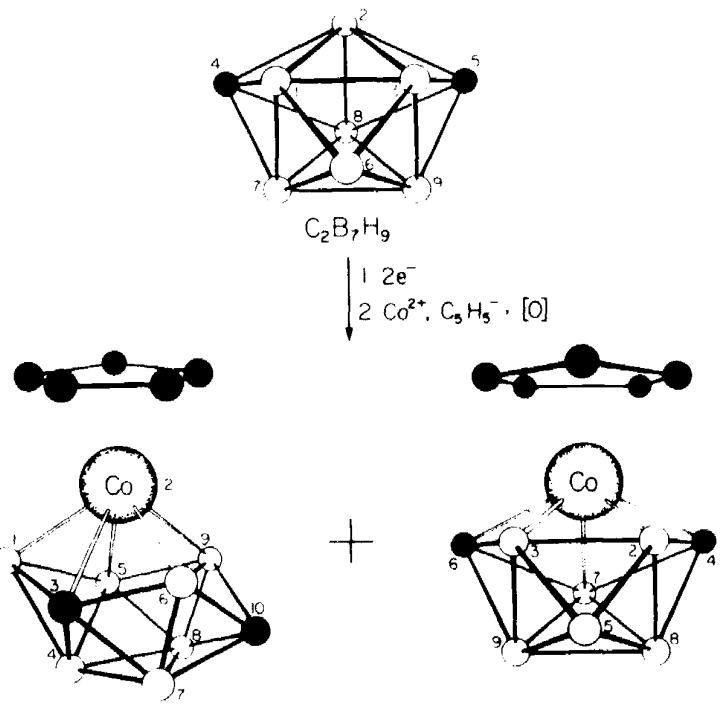

$2.3,10 \cdot \mathrm{C}_{5} \mathrm{H}_{5} \mathrm{CoC}_{2} \mathrm{~B}_{7} \mathrm{H}_{9}$

I. 4.6- $\mathrm{C}_{5} \mathrm{H}_{5} \mathrm{CoC}_{2} \mathrm{~B}_{6} \mathrm{H}_{8}$

$1,2,3 \cdot \mathrm{C}_{5} \mathrm{H}_{5} \mathrm{CoC}_{2} \mathrm{~B}_{8} \mathrm{H}_{10}$

$\mathrm{O}=\mathrm{CH}$

( $=\mathrm{BH}$

Figure 5. Polyhedral expansion of $4,5-\mathrm{C}_{2} \mathrm{~B}_{7} \mathrm{H}_{9}$. 
was found to be a positional isomer of the substance originally prepared by polyhedral expansion of $1,7-\mathrm{C}_{2} \mathrm{~B}_{6} \mathrm{H}_{8}$ mentioned previously; the other product, a bimetallic 12-vertex polyhedral species, contained one boron vertex more than was present in the starting material. Careful analysis indicated no contamination of the 4,5- $\mathrm{C}_{2} \mathrm{~B}_{7} \mathrm{H}_{9}$ with higher carborane impurities, indicating that an apparent boron transfer process occurred during polyhedral expansion. An x-ray crystal structure determination was recently completed on the bimetallic complex ${ }^{19}$ and again proved the presence of a cobalt-cobalt bond; in this compound the metal-metal distance is even shorter than in $\left(\mathrm{C}_{5} \mathrm{H}_{5}\right) \mathrm{Co}_{2} \mathrm{C}_{2} \mathrm{~B}_{6} \mathrm{H}_{8}$, the $\mathrm{Co}-\mathrm{Co}$ distance being $2.39 \AA$.

Polyhedral expansion of two of the isomeric $\mathrm{C}_{2} \mathrm{~B}_{8} \mathrm{H}_{10}$ carboranes ${ }^{18,20}$ produced a wide variety of products; the reaction sequence for the $1,6-\mathrm{C}_{2} \mathrm{~B}_{8} \mathrm{H}_{10}$ isomer is depicted in Figure 6. In addition to the normal product of polyhedral expansion, $\mathrm{C}_{5} \mathrm{H}_{5} \mathrm{CoC}_{2} \mathrm{~B}_{8} \mathrm{H}_{10}$, monometallic species with seven and nine boron vertices were isolated, two different bimetallic $\left(\mathrm{C}_{5} \mathrm{H}_{5}\right)_{2} \mathrm{Co}_{2} \mathrm{C}_{2} \mathrm{~B}_{8} \mathrm{H}_{10}$ compounds were found, and ionic complexes of the formula $\mathrm{Co}\left(\mathrm{C}_{2} \mathrm{~B}_{8} \mathrm{H}_{10}\right)_{2}^{-7}$ were also detected. Even more interesting were the minor products isolated from this reaction. One such compound, formulated as $\left(\mathrm{C}_{5} \mathrm{H}_{5}\right) \mathrm{CoC}_{2} \mathrm{~B}_{8} \mathrm{H}_{9}$ $\left(\mathrm{C}_{2} \mathrm{~B}_{8} \mathrm{H}_{9}\right)$, has been spectrally identified as a carborane-substituted polyhedral expansion product in which the normal expansion species, $\mathrm{C}_{5} \mathrm{H}_{5} \mathrm{Co}$ $\mathrm{C}_{2} \mathrm{~B}_{8} \mathrm{H}_{10}$, is substituted at one of the polyhedral carbon atom positions by a

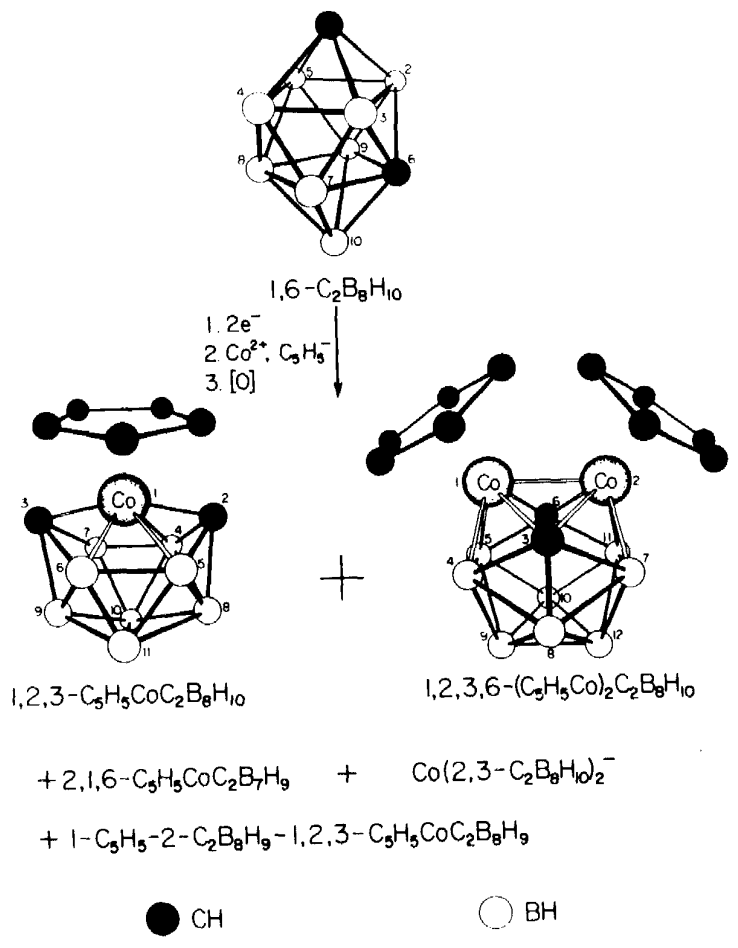

Figure 6. Polyhedral expansion of $1,6-\mathrm{C}_{2} \mathrm{~B}_{8} \mathrm{H}_{10}$. 


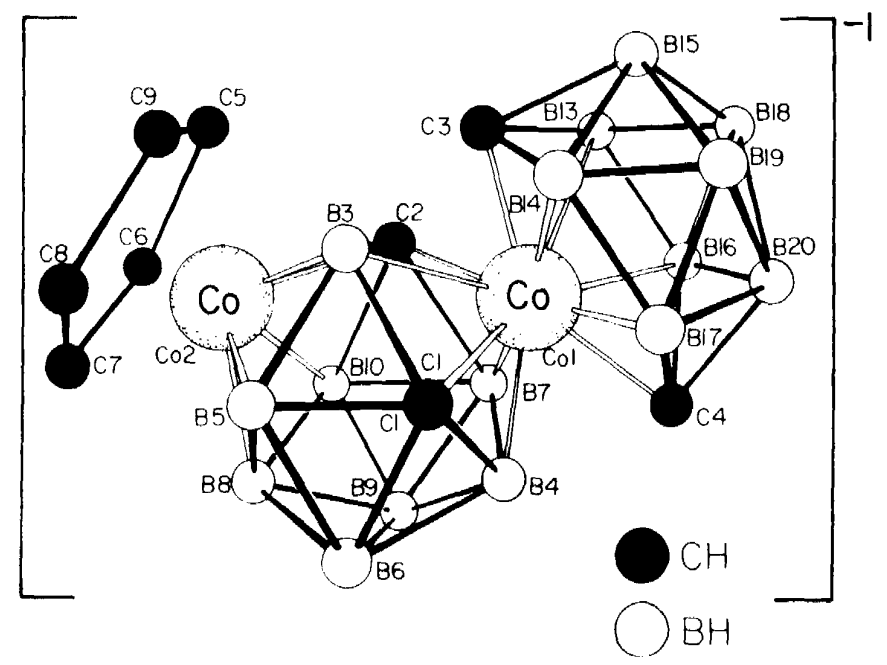

Figure 7. Structure of $\mathrm{C}_{5} \mathrm{H}_{5} \mathrm{CoC}_{2} \mathrm{~B}_{8} \mathrm{H}_{10} \mathrm{CoC}_{2} \mathrm{~B}_{8} \mathrm{H}_{10}{ }^{22}$.

terminal $\mathrm{C}_{2} \mathrm{~B}_{8} \mathrm{H}_{9}$ carborane group also bonded through carbon. Another product. isolated from the polyhedral expansion of $1.6-\mathrm{C}_{2} \mathrm{~B}_{8} \mathrm{H}_{10}$ at -80 . and formulated as $\mathrm{C}_{5} \mathrm{H}_{5} \mathrm{CoC}_{2} \mathrm{~B}_{8} \mathrm{H}_{10} \mathrm{CoC}_{2} \mathrm{~B}_{8} \mathrm{H}_{10}$, was proposed ${ }^{21}$ to contain both a monodentate and a bidentate $\mathrm{C}_{2} \mathrm{~B}_{8} \mathrm{H}_{10}$ ligand. This structure has been confirmed by $\mathrm{x}$-ray diffraction ${ }^{22}$ and is shown in Figure 7. The polyhedral expansion reaction, when performed on $2,3-\mathrm{C}_{2} \mathrm{~B}_{9} \mathrm{H}_{11}$, was found to produce two isomeric products of normal 1-vertex expansion, having the formula $\mathrm{C}_{5} \mathrm{H}_{5} \mathrm{CoC}_{2} \mathrm{~B}_{9} \mathrm{H}_{11}$, in addition to several other species more readily produced by other means ${ }^{21}$.

When polyhedral expansion was attempted with the icosahedral carborane, $1.2-\mathrm{C}_{2} \mathrm{~B}_{10} \mathrm{H}_{12}{ }^{23,24}$, the corresponding expansion product, $\mathrm{C}_{5} \mathrm{H}_{5^{-}}$$\mathrm{CoC}_{2} \mathrm{~B}_{10} \mathrm{H}_{12}$. was isolated in appreciable yield. This species was the first 13-vertex closed polyhedral borane species prepared.

The original red product was found to undergo facile thermal polyhedral rearrangements to form orange and red-orange isomeric $\mathrm{C}_{5} \mathrm{H}_{5} \mathrm{CoC}_{2} \mathrm{~B}_{8} \mathrm{H}_{12}$

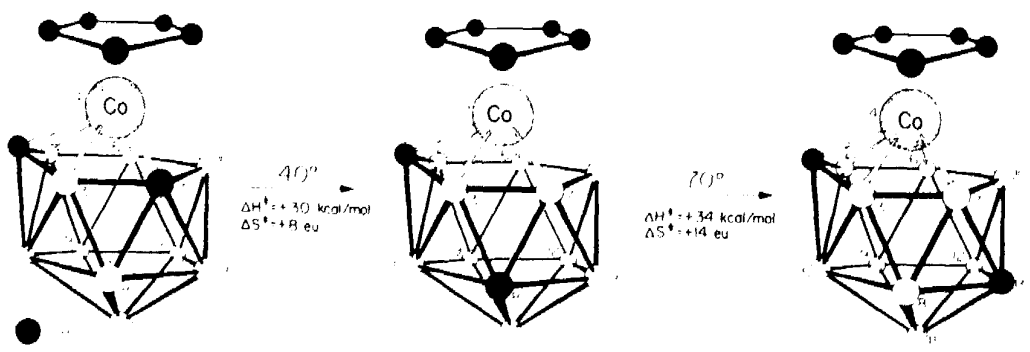

Figure 8 . Thermal polyhedral rearrangement of $\mathrm{C}_{5} \mathrm{H}_{5} \mathrm{CoC}_{2} \mathrm{~B}_{10} \mathrm{H}_{12}$. 
complexes; the proposed isomeric structures are shown in Figure 8. The red isomer has been shown crystallographically to possess the depicted structure $^{25}$; the other isomers are believed to have similar geometries and the carbon atom positions have been assigned on the basis of ${ }^{11} B$ n.m.r. spectra and general observations on the course of polyhedral rearrangements. The red isomer is fluxional in solution ${ }^{24}$ as shown by variable-temperature ${ }^{11}$ B n.m.r. measurements. This behaviour, schematically shown in Figure 9 , consists of a rapid intramolecular racemization in which the two enantiomers (carbon atoms in 1,6 or 1,7 positions) rapidly interconvert, and can be visualized as proceeding via a diamond-square-diamond (dsd) intermediate ${ }^{26}$.

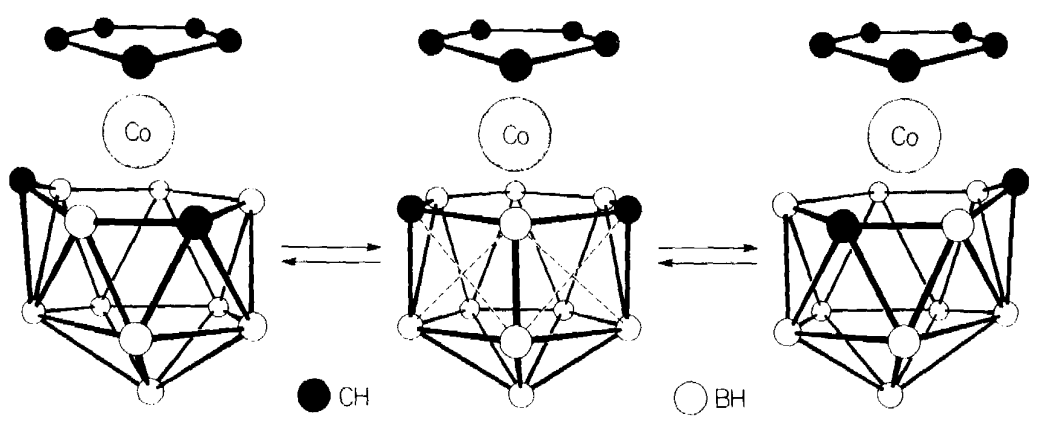

Figure 9. Intramolecular racemization of red $\mathrm{C}_{5} \mathrm{H}_{5} \mathrm{CoC}_{2} \mathrm{~B}_{10} \mathrm{H}_{12}$ visualized as proceeding through a diamond square-diamond (dsd) intermediate.

(B) Polyhedral expansion of metallocarboranes

We have shown above that $\mathrm{C}_{2} \mathrm{~B}_{n} \mathrm{H}_{n+2}$ carboranes may undergo polyhedral expansion to produce metallocarboranes having one vertex more than was present in the starting carborane. The detection of bimetallic products of polyhedral expansion in some of these reactions indicated the possibility that metallocarboranes could be used as starting materials in polyhedral expansion to provide a direct route to bimetallic complexes. Further polyhedral expansion to form even higher polymetallocarboranes would also be a distinct possibility.

The first report of the direct synthesis of a bimetallocarborane by polyhedral expansion of a monometallic starting material ${ }^{27}$ involved the expansion of $\mathrm{C}_{5} \mathrm{H}_{5} \mathrm{CoC}_{2} \mathrm{~B}_{8} \mathrm{H}_{10}$, itself synthesized by the polyhedral expansion of 1,6- $\mathrm{C}_{2} \mathrm{~B}_{8} \mathrm{H}_{10}$, and produced a compound having the desired formula, $\left(\mathrm{C}_{5} \mathrm{H}_{5}\right)_{2} \mathrm{Co}_{2} \mathrm{C}_{2} \mathrm{~B}_{8} \mathrm{H}_{10}$. This reaction sequence is shown in Figure 10. The products formed in this reaction had been previously synthesized in the polyhedral expansion of $1,6-\mathrm{C}_{2} \mathrm{~B}_{8} \mathrm{H}_{10}$, thus no new metallocarboranes were formed in this reaction. However, the yield of the icosahedral bimetallic complex was increased nearly tenfold over the previous synthesis. 

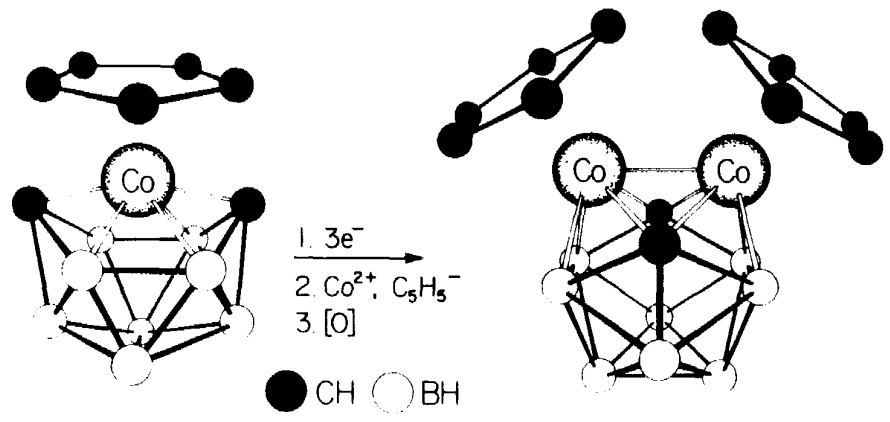

Figure 10. Polyhedral expansion of $1-\mathrm{C}_{5} \mathrm{H}_{5} \mathrm{Co}-2.3-\mathrm{C}_{2} \mathrm{~B}_{8} \mathrm{H}_{10}$.

Polyhedral expansion of $\mathrm{C}_{5} \mathrm{H}_{5} \mathrm{Co}-1,6-\mathrm{C}_{2} \mathrm{~B}_{7} \mathrm{H}_{9}{ }^{28}$ produced several compounds including the desired 11-vertex bimetallocarborane $\left(\mathrm{C}_{5} \mathrm{H}_{5}\right)_{2^{-}}$ $\mathrm{Co}_{2} \mathrm{C}_{2} \mathrm{~B}_{7} \mathrm{H}_{9}{ }^{28.29}$. A side product of this reaction had the formula $\left(\mathrm{C}_{5} \mathrm{H}_{5}\right)_{3^{-}}$ $\mathrm{Co}_{3} \mathrm{C}_{2} \mathrm{~B}_{7} \mathrm{H}_{9}$, and spectral data indicate this complex to be the first trimetallic metallocarborane ever observed. The reaction sequence used in
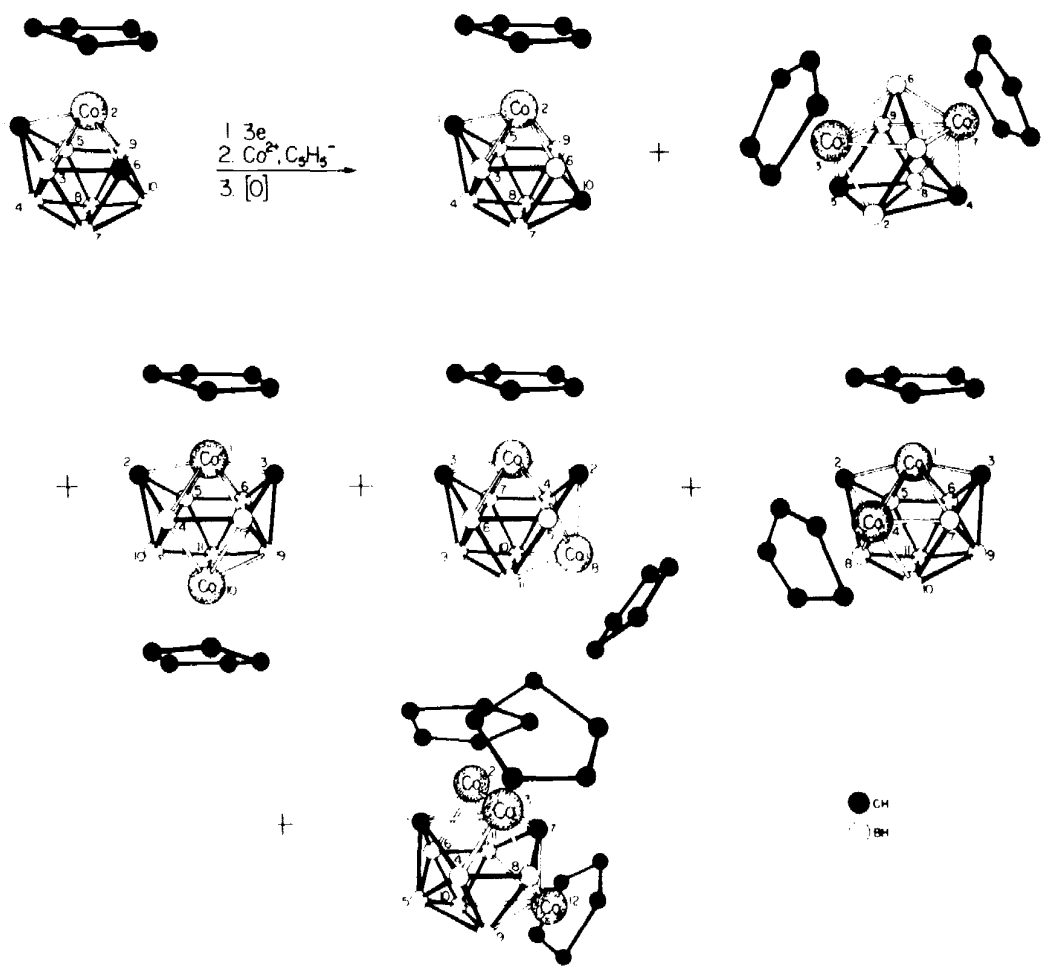

Figure 11. Polyhedral expansion of $2-\mathrm{C}_{5} \mathrm{H}_{5} \mathrm{Co}-1,6-\mathrm{C}_{2} \mathrm{~B}_{7} \mathrm{H}_{4}$. 
this preparation is presented in Figure 11. The trimetallic complex, presumably having icosahedral geometry, was found to decompose in solution over a period of days to the bimetallic octadecahedral product, $\left(\mathrm{C}_{5} \mathrm{H}_{5}\right)_{2}$ $\mathrm{Co}_{2} \mathrm{C}_{2} \mathrm{~B}_{7} \mathrm{H}_{9}$, the first product separated from this reaction mixture and formed by 1-vertex expansion. Thus, although the synthesis of the trimetallic complex had moved the areas of metal cluster chemistry and polyhedral borane chemistry one step closer together, the ready decomposition of the

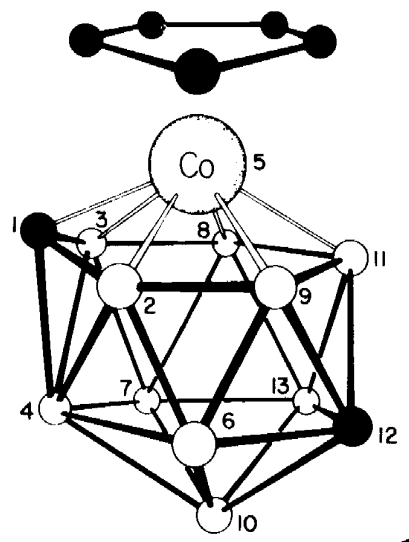

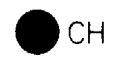
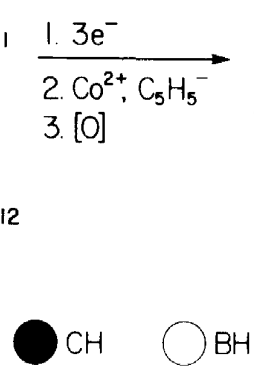
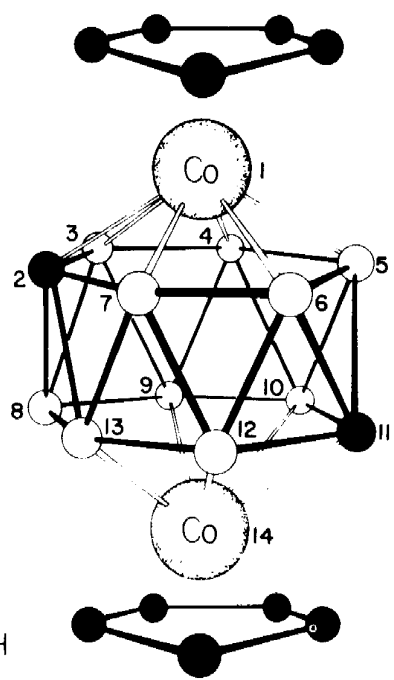

Figure 12. Synthesis of a 14-vertex bimetallocarborane by polyhedral expansion.

trimetallic species indicates that additional factors must be operative in polymetallocarborane chemistry. The incorporation of several metal vertices in a polyhedral metallocarborane apparently lowers the stability of the resulting product, perhaps due to large concentrations of charge or to steric effects caused by the longer bond lengths and bulky $\mathrm{C}_{5} \mathrm{H}_{5}^{-}$ligand associated with the metal atoms.

The 13-vertex metallocarboranes also undergo polyhedral expansion, and the first 14-vertex metallocarborane has been synthesized in this manner ${ }^{30}$. The reaction sequence is depicted in Figure 12. Reduction of the red-orange isomer of $\left(\mathrm{C}_{5} \mathrm{H}_{5}\right) \mathrm{CoC}_{2} \mathrm{~B}_{10} \mathrm{H}_{12}$ in THF solution with three equivalents of sodium metal, employing naphthalene as an electron carrier, was followed by addition of excess $\mathrm{Na}^{+} \mathrm{C}_{5} \mathrm{H}_{5}^{-}$and $\mathrm{CoCl}_{2}$. Oxidative work-up of the reaction mixture afforded a series of products, the primary species being a bimetallic complex, $\left(\mathrm{C}_{5} \mathrm{H}_{5}\right)_{2} \mathrm{Co}_{2} \mathrm{C}_{2} \mathrm{~B}_{10} \mathrm{H}_{12}$, which appears to have the geometry of the closed 14-vertex polyhedron depicted in Figure 12. Although other 14-vertex geometries are possible, the proposed structure incorporates coordination numbers for the constituent atoms most consistent with those observed in other metallocarboranes, and is the obvious extension of the 
13-vertex structure also shown in Figure 12. Several isomeric structures are possible in this complex, depending upon the relative positions of the polyhedral carbon atoms. The structure shown has the cobalt atoms at highcoordinate vertices, as is generally observed in cobaltacarboranes, and the carbon atoms in the same relative positions as proposed for the starting material. A second isomer of this 14-vertex compound is produced upon polyhedral expansion of the orange isomer of $\mathrm{C}_{5} \mathrm{H}_{5} \mathrm{CoC}_{2} \mathrm{~B}_{10} \mathrm{H}_{12}{ }^{28}$; crystallographic studies of these compounds are under investigation to conclusively determine the geometries of these large polyhedra.

Although most of the polyhedral expansion reactions discussed so far have incorporated cobalt as the metallic vertex (or vertices), other transition metals may also be incorporated into carborane polyhedra by this method; the synthesis and characterization of 13-vertex polyhedra containing iron. nickel, molybdenum and tungsten have been previously discussed ${ }^{24}$. Expansion of monometallocarboranes allows the possibility of producing bimetallocarboranes with two different metal atom vertices. Such substances have recently been prepared ${ }^{31}$ in which both iron and cobalt vertices are present in a 13-vertex bimetallocarborane, and other examples are under study.

It has been shown that mono-, bi- and trimetallocarboranes may be successfully prepared by the use of polyhedral expansion conditions. Although we have been able to produce closed polyhedra larger than those observed in boranes or carboranes, such an increase in size may prove disadvantageous in the long run. We have already mentioned one example of the facile loss of a metal vertex from the icosahedral trimetallic compound, and such behaviour could prove more common as polyhedral size and number of metal vertices increase. A means of decreasing the size could be of assistance in our search for polyhedra with larger numbers of metal vertices. Such a means may be available in the recently developed polyhedral contraction reaction. An offshoot of the latter reaction sequence affords another synthetic route to polymetallocarboranes, which we term polyhedral subrogation.

\section{(C) Polyhedral contraction and polyhedral subrogation}

During the preparation of the bis(dicarbollyl)cobalt(III) anion by the deprotonation of $\mathrm{C}_{2} \mathrm{~B}_{9} \mathrm{H}_{12}$ in strong aqueous base, it was noted that coloured solutions remained upon separation of all the desired product. Further examination of these solutions revealed the presence of new anionic metallocarborane species which incorporated two and three metals per ion. Elemental analysis indicated the presence of a new type of carborane unit, formulated as the $\mathrm{C}_{2} \mathrm{~B}_{8} \mathrm{H}_{10}^{4-}$ ion ${ }^{32}$, and $\mathrm{x}$-ray crystallographic investigations revealed the structures shown in Figure 13 33,34 . It is convenient to think of these molecules as being derived from bis(dicarbollyl)cobalt(III) complexes which have undergone cage degradation to produce the bidentate $\mathrm{C}_{2} \mathrm{~B}_{8} \mathrm{H}_{10}^{4--}$ (dicarbacanastide) ion. Although the $\mathrm{C}_{2} \mathrm{~B}_{9} \mathrm{H}_{12}^{-}$ion, formed by degradation of $1,2 \cdot \mathrm{C}_{2} \mathrm{~B}_{10} \mathrm{H}_{12}$. Figure $\mathrm{l}$, is inert to further base degradation, apparently the formation of the metallocarborane labilizes an additional boron vertex in the icosahedral complex. Thus, prolonged treatment of the metallocarborane with a strong base in the presence of excess Co(II) effected degradation with subsequent formation of the observed products. The insertion of a 

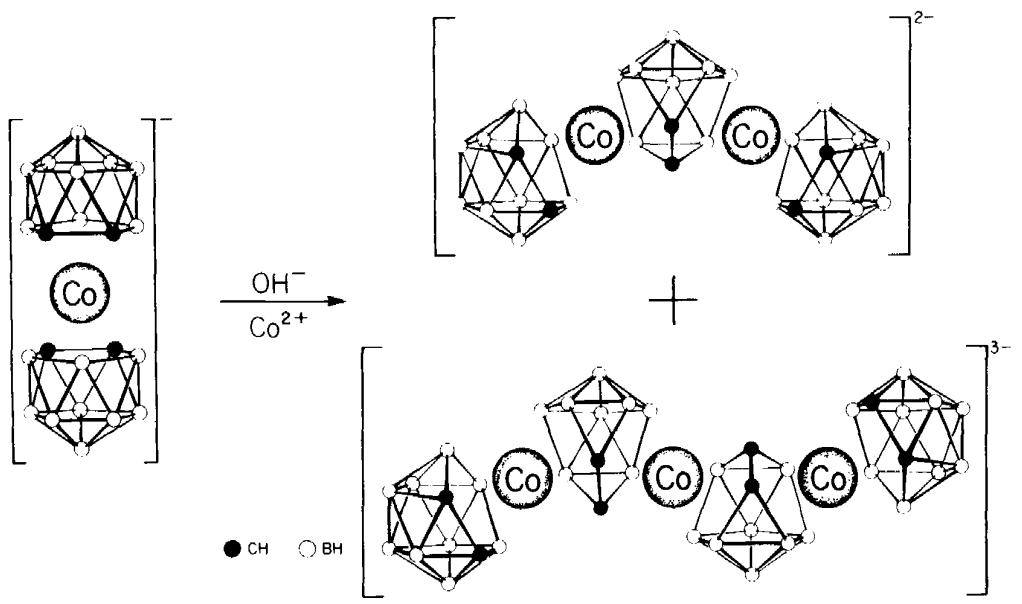

Figure 13. Structures of polymetallocarboranes produced by polyhedral subrogation of $\left[\left(1,2-\mathrm{C}_{2} \mathrm{~B}_{9} \mathrm{H}_{11}\right)_{2} \mathrm{Co}\right]^{-}$.

dicarbollylcobalt vertex into the degraded cage is thought to be due to the existence of free $\mathrm{C}_{2} \mathrm{~B}_{9} \mathrm{H}_{11}^{2-}$ ions in the reaction mixture. This was the first instance in which chemistry other than substitution reactions was demonstrated with metallocarboranes, and led to two synthetic methods which we have recently employed in metallocarborane synthesis, the polyhedral contraction and polyhedral subrogation reactions.

When $\mathrm{C}_{5} \mathrm{H}_{5} \mathrm{CoC}_{2} \mathrm{~B}_{9} \mathrm{H}_{11}$ is treated with strong base, removal of a polyhedral boron atom occurs as described above; however, in the absence of

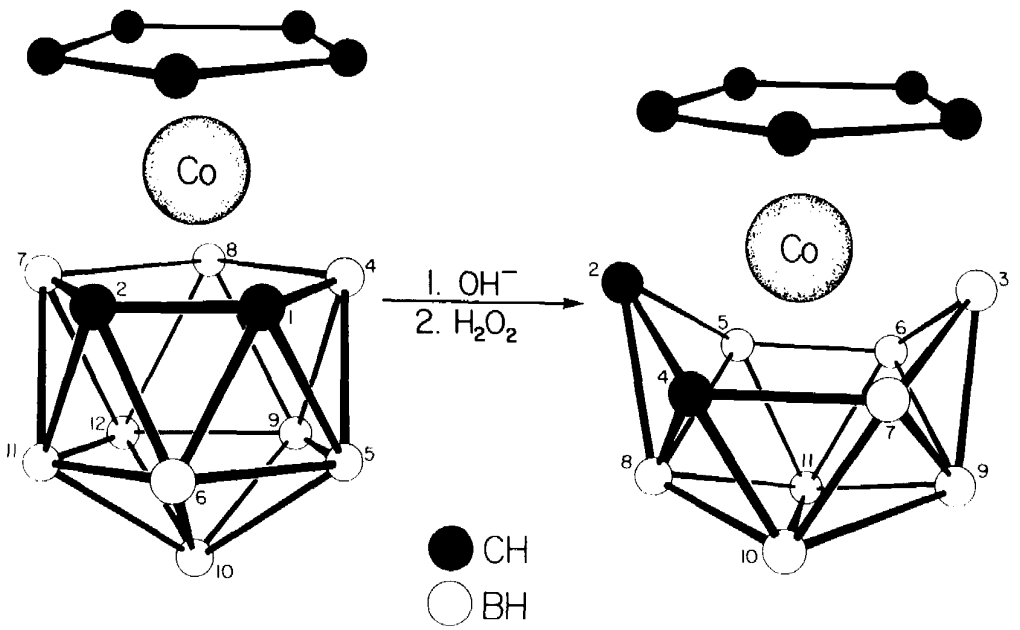

Figure 14. Polyhedral contraction of $3-\mathrm{C}_{5} \mathrm{H}_{5} \mathrm{Co}-1,2-\mathrm{C}_{2} \mathrm{~B}_{9} \mathrm{H}_{11}$ to $1-\mathrm{C}_{5} \mathrm{H}_{5} \mathrm{Co}-2,4-\mathrm{C}_{2} \mathrm{~B}_{8} \mathrm{H}_{10}$. 

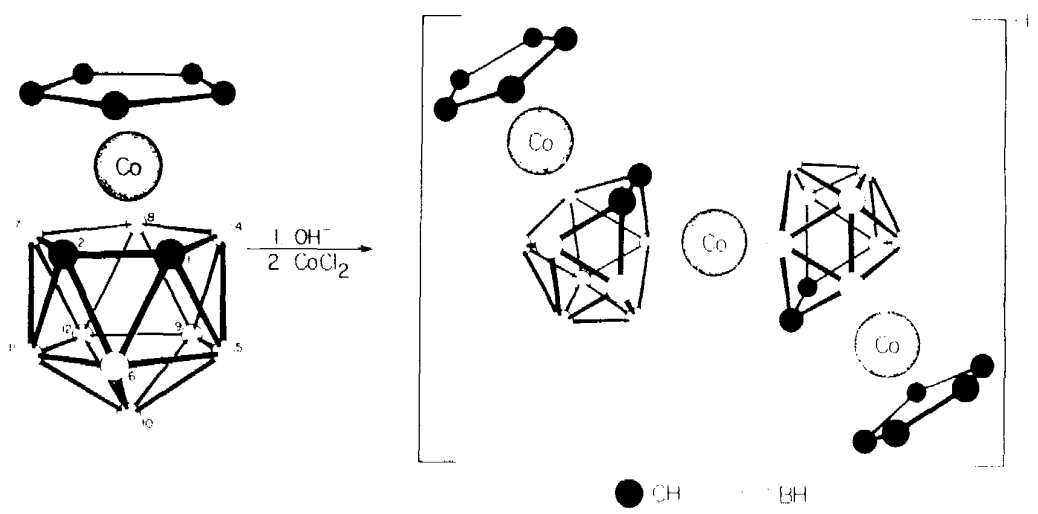

Figure 15. Polyhedral subrogation of $3-\mathrm{C}_{5} \mathrm{H}_{5} \mathrm{Co}-1.2-\mathrm{C}_{2} \mathrm{~B}_{4} \mathrm{H}_{11}$.

additional transition metal salts. complexation of this degraded cage does occur. and oxidation of the resulting solution produces a high yield of a compound having the formula $\mathrm{C}_{5} \mathrm{H}_{5} \mathrm{CoC}_{2} \mathrm{~B}_{8} \mathrm{H}_{10}{ }^{35}$ and slown to be isomeric (carbon atoms in the 2 and 4 positions) with the complex formed from the polyhedral expansion of $\mathrm{C}_{2} \mathrm{~B}_{8} \mathrm{H}_{10}$. This reaction, termed 'polyhedral contraction: consists of degradative removal of a polyhedral $\{\mathrm{BH}\}$ vertex followed by two-electron oxidation to a closed polyhedron and affords the next lower metallocarborane homologue. This reaction sequence is depicted in Figure 14. It is believed that initial base attack occurs at the boron atom in position 6 in the starting material. It should be the most readily attacked by nucleophiles since it is positioned between the two electropositive carbon atoms. Polyhedral rearrangement must occur to generate the contracted
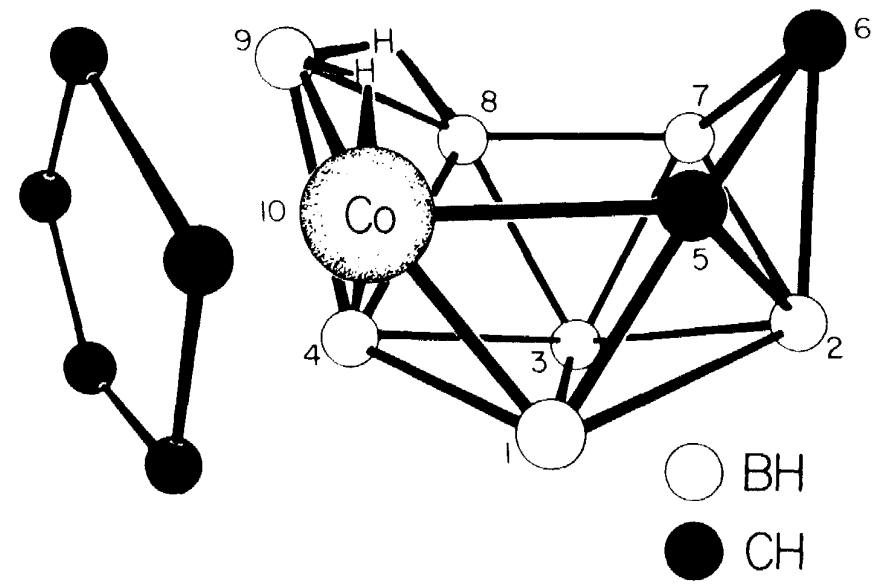

Figure 16 . Structure of the nido-metallocarborane product produced in the polyhedral contraction of $1-\mathrm{C}_{5} \mathrm{H}_{5} \mathrm{Co}-2.4-\mathrm{C}_{2} \mathrm{~B}_{8} \mathrm{H}_{10}$. 
product. The intermediate species can be trapped, however, when the degradation is performed in the presence of transition metal ions ${ }^{36}$. This reaction, in which a polyhedral $\{\mathrm{BH}\}$ vertex is removed and replaced by a transition metal vertex, has been termed 'polyhedral subrogation', and is illustrated in Figure 15.

Further evidence for the existence of nido-metallocarborane intermediates was obtained from the polyhedral contraction of $1-\mathrm{C}_{5} \mathrm{H}_{5} \mathrm{Co}-2,4-\mathrm{C}_{2} \mathrm{~B}_{8} \mathrm{H}_{10}$ in the absence of cobalt ${ }^{37}$. In this case the protonated nido monometallic intermediate was actually isolated. The structure of this species has been determined crystallographically ${ }^{38}$ and is shown in Figure 16. The positions of the bridging hydrogen atoms indicated in the figure were unambiguously located in the X-ray data, which were collected at $-150^{\circ}$. Pyrolysis of $\mathrm{C}_{5} \mathrm{H}_{5}$ $\mathrm{CoC}_{2} \mathrm{~B}_{7} \mathrm{H}_{11}$ produces the contraction product 1- $\mathrm{C}_{5} \mathrm{H}_{5} \mathrm{Co}-2,9-\mathrm{C}_{2} \mathrm{~B}_{7} \mathrm{H}_{9}$, with concomitant loss of $\mathrm{H}_{2}$.

When the polyhedral contraction reaction was performed on the orange isomer of the 13-vertex metallocarborane $\mathrm{C}_{5} \mathrm{H}_{5} \mathrm{CoC}_{2} \mathrm{~B}_{10} \mathrm{H}_{12}$, an anionic product of composition $\mathrm{C}_{5} \mathrm{H}_{5} \mathrm{CoCB}_{7} \mathrm{H}_{8}^{-}$was isolated ${ }^{39}$. Formation of this species required the removal of three $\{\mathrm{BH}\}$ and one $\{\mathrm{CH}\}$ vertices. an unprecedented extent of polyhedral degradation. A crystallographic study ${ }^{40}$ has shown this compound to have the overall geometry of a tricapped trigonal prism, as shown in Figure 17.

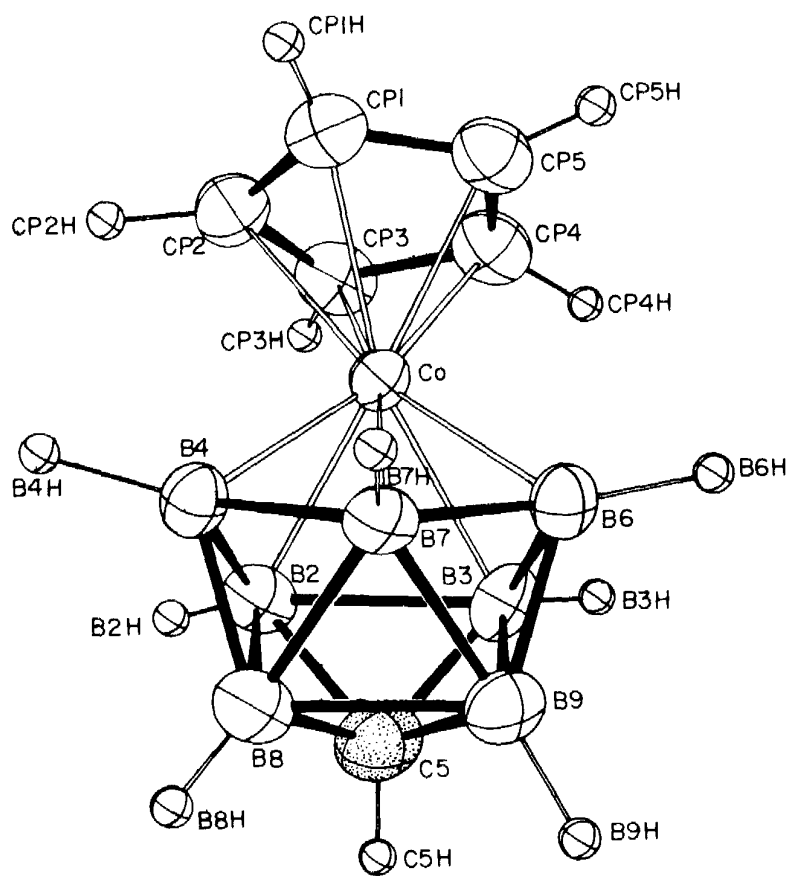

Figure 17. Structure of the polyhedral contraction product of orange $\mathrm{C}_{5} \mathrm{H}_{5} \mathrm{Co}_{0}-\mathrm{C}_{2} \mathrm{~B}_{10} \mathrm{H}_{12}$. 
Polyhedral subrogation may be effected with either the orange or red-orange isomers of $\mathrm{C}_{5} \mathrm{H}_{5} \mathrm{CoC}_{2} \mathrm{~B}_{10} \mathrm{H}_{12}$. affording 13-vertex bimetallocarboranes. This subrogation reaction is successful with either iron(II) or cobalt(II) ions, thus affording another route to heterobimetallocarboranes $^{31,41}$.

Heterobimetallocarboranes may also be synthesized by combining polyhedral contraction and polyhedral expansion. The 9-vertex monocarbon metallocarborane anion $\mathrm{C}_{5} \mathrm{H}_{5} \mathrm{CoCB}_{7} \mathrm{H}_{8}^{-}$, produced from the polyhedral contraction of the orange $\mathrm{C}_{5} \mathrm{H}_{5} \mathrm{CoC}_{2} \mathrm{~B}_{10} \mathrm{H}_{12}$. undergoes polyhedral expansion in the presence of $\mathrm{Ni}(\mathrm{II})$ to produce the neutral complex $\left(\mathrm{C}_{5} \mathrm{H}_{5}\right)_{2} \mathrm{CoNiCB}_{7}-$ $\mathrm{H}_{8}{ }^{42}$. The choice of nickel to effect this expansion was based on recent considerations ${ }^{43}$ which indicate that a $\left\{\left(\mathrm{C}_{5} \mathrm{H}_{5}\right) \mathrm{Co}\right\}$ unit is electronically similar to a polyhedral $\{\mathrm{BH}\}$ vertex, contributing two electrons and three orbitals to polyhedral bonding. while $\left\{\left(\mathrm{C}_{5} \mathrm{H}_{5}\right) \mathrm{Ni}\right\}$. like a polyhedral $\{\mathrm{CH}\}$ unit. contributes three orbitals and three electrons to polyhedral bonding.

\section{(D) Thermal metal transfer}

We recently discovered an exciting new approach to the synthesis of metallocarboranes in an attempt to effect a polyhedral rearrangement upon $1-\mathrm{C}_{5} \mathrm{H}_{5} \mathrm{Co}-2.3-\mathrm{C}_{2} \mathrm{~B}_{8} \mathrm{H}_{10}{ }^{44}$. When this compound, in the vapour phase. was passed through a hot tube maintained at $525^{\prime}$, the sublimed products included a significant amount of isomeric $\left(\mathrm{C}_{5} \mathrm{H}_{5}\right)_{2} \mathrm{Co}_{2} \mathrm{C}_{2} \mathrm{~B}_{8} \mathrm{H}_{10}$ complexes. Increased yields were obtained when the pyrolysis was performed in solution; after heating for seven hours at $235^{\circ}$ in hexadecane, six isomeric $\left(\mathrm{C}_{5} \mathrm{H}_{5}\right)_{2} \mathrm{Co}_{2}$ $\mathrm{C}_{2} \mathrm{~B}_{8} \mathrm{H}_{10}$ compounds were produced in 32 per cent overall yield based on consumed starting material.
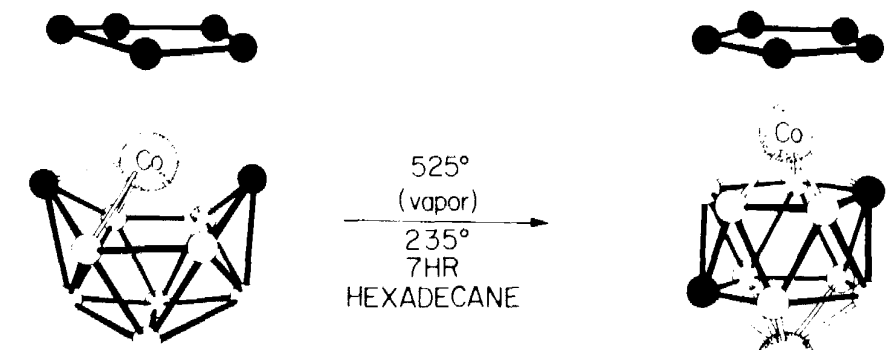

$$
1-\mathrm{C}_{5} \mathrm{H}_{5}-\mathrm{I}-\mathrm{CO}-2,3-\mathrm{C}_{2} \mathrm{~B}_{8} \mathrm{H}_{10}
$$
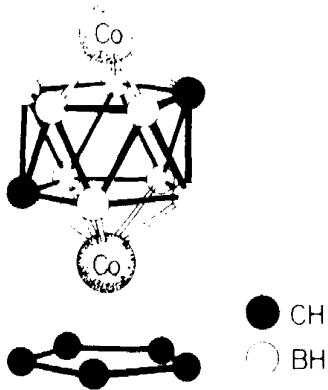

$\left(\mathrm{C}_{5} \mathrm{H}_{5}\right)_{2} \mathrm{CO}_{2} \mathrm{C}_{2} \mathrm{~B}_{8} \mathrm{H}_{10}$

( +5 OTHER ISOMERS)

$$
\left[\left(\mathrm{C}_{5} \mathrm{H}_{5}\right)_{2} \mathrm{CO}\right]^{+}\left[\left(2,3-\mathrm{C}_{2} \mathrm{~B}_{8} \mathrm{H}_{10}\right)_{2} \mathrm{CO}\right] \frac{\mathrm{HOT} \text { TUBE }}{270^{\circ}}-\left(\mathrm{C}_{5} \mathrm{H}_{5}\right)_{2} \mathrm{CO}_{2} \mathrm{C}_{2} \mathrm{~B}_{8} \mathrm{H}_{10}
$$

Figure 18. Schematic representation of thermal metal transfer process. 
Even more surprising was the production of these same compounds when the ionic substrate $\left[\left(\mathrm{C}_{5} \mathrm{H}_{5}\right)_{2} \mathrm{Co}\right]^{+}\left[\mathrm{Co}\left(\mathrm{C}_{2} \mathrm{~B}_{8} \mathrm{H}_{10}\right)_{2}\right]^{-}$was heated. in solution or in the vapour state. The product yield was comparable to that obtained by pyrolysis of the neutral compound. These results are schematically presented in Figure 18.

Thermal polyhedral rearrangements of carboranes have been known for some time, but the preparation of an $n+1$-vertex bimetallocarborane by pyrolysis of an $n$-vertex metallocarborane was unprecedented. The preparation of neutral bimetallic complexes by pyrolysis of cobalticinium salts of commo-metallocarborane anions was an even less expected result of this work. Further studies on the pyrolysis of compounds of this type are under study; it is possible that this, too, may prove to be a general route to the preparation of new and interesting metallocarboranes.

\section{CATALYTIC PROPERTIES OF METALLOCARBORANES}

Although the role of organometallic complexes in catalysing numerous organic reactions has been well documented, little work has been published on the study of metalloboranes or metallocarboranes as potential catalysts. The thermal, oxidative and chemical stabilities of these substances make them potentially useful. However, their kinetic stabilities may preclude catalytic behaviour, which demands the ability to activate substrates to further chemical reaction.

Our first venture into this area was the demonstration that the wellknown ortho-metallation of aryl groups in suitable transition metal complexes could also be effected on a carborane polyhedron. Reaction of $\left[\operatorname{Ir}\left(\mathrm{C}_{8} \mathrm{H}_{14}\right)_{2} \mathrm{Cl}\right]_{2}$ with $\mathrm{Me}_{2} \mathrm{P}\left(\mathrm{C}_{2} \mathrm{~B}_{10} \mathrm{H}_{11}\right)$ produced the carboranylphosphine analogue of $\left[\left(\mathrm{C}_{6} \mathrm{H}_{5}\right)_{3} \mathrm{P}\right]_{3} \mathrm{IrCl}$, a four-coordinate formal iridium(I) compound $^{45}$. This species was found to undergo facile intramolecular oxidativeaddition to produce a complex which exhibited a new infra-red absorption, characteristic of an iridium-hydrogen stretch. Deuteration experiments have established that oxidative-addition occurs at a polyhedral $\{\mathrm{BH}\}$ vertex. Figure 19 illustrates our present concept of this reaction.

We next investigated the behaviour of the carboranylphosphine with deuterium gas and $\left[\left(\mathrm{C}_{6} \mathrm{H}_{5}\right)_{3} \mathrm{P}\right]_{3} \mathrm{RuHCl}$. a catalyst for the specific ortho-deuteration of triphenylphosphine. It was found that more deuterium was incorporated than could be accounted for by only an ortho-metallation type mechanism. Further studies have shown that a variety of homogeneous catalysts can effect hydrogen-deuterium exchange at boron on a wide variety of non-complexing substrates ${ }^{46}$. For example, $\left[\left(\mathrm{C}_{6} \mathrm{H}_{5}\right)_{3} \mathrm{P}\right]_{3} \mathrm{RuHCl}$ catalyses the $\mathrm{H}-\mathrm{D}$ exchange on boron in $1,2-\mathrm{C}_{2} \mathrm{~B}_{10} \mathrm{H}_{12}$. The order of rates of incorporation at available vertices is $3,6>4,5,7,11>8,9,10,12$. This is the reverse of the order observed for electrophilic substitution, e.g. halogenation. The same catalyst reacts with $\mathrm{B}_{10} \mathrm{H}_{14}$, but the resulting mixture shows an even greater degree of selectivity for the catalytic deuteration of $B_{10} \mathrm{H}_{14}$, in the order

$$
6,9>5,7,8,10>3,4 \gg 1,2 \mu .
$$

Studies of catalytic behaviour in the carborane area took on a different aspect with the synthesis of $\left[\left(\mathrm{C}_{6} \mathrm{H}_{5}\right)_{3} \mathrm{P}\right]_{2} \mathrm{RhH}\left(\mathrm{C}_{2} \mathrm{~B}_{9} \mathrm{H}_{11}\right)$. This compound 

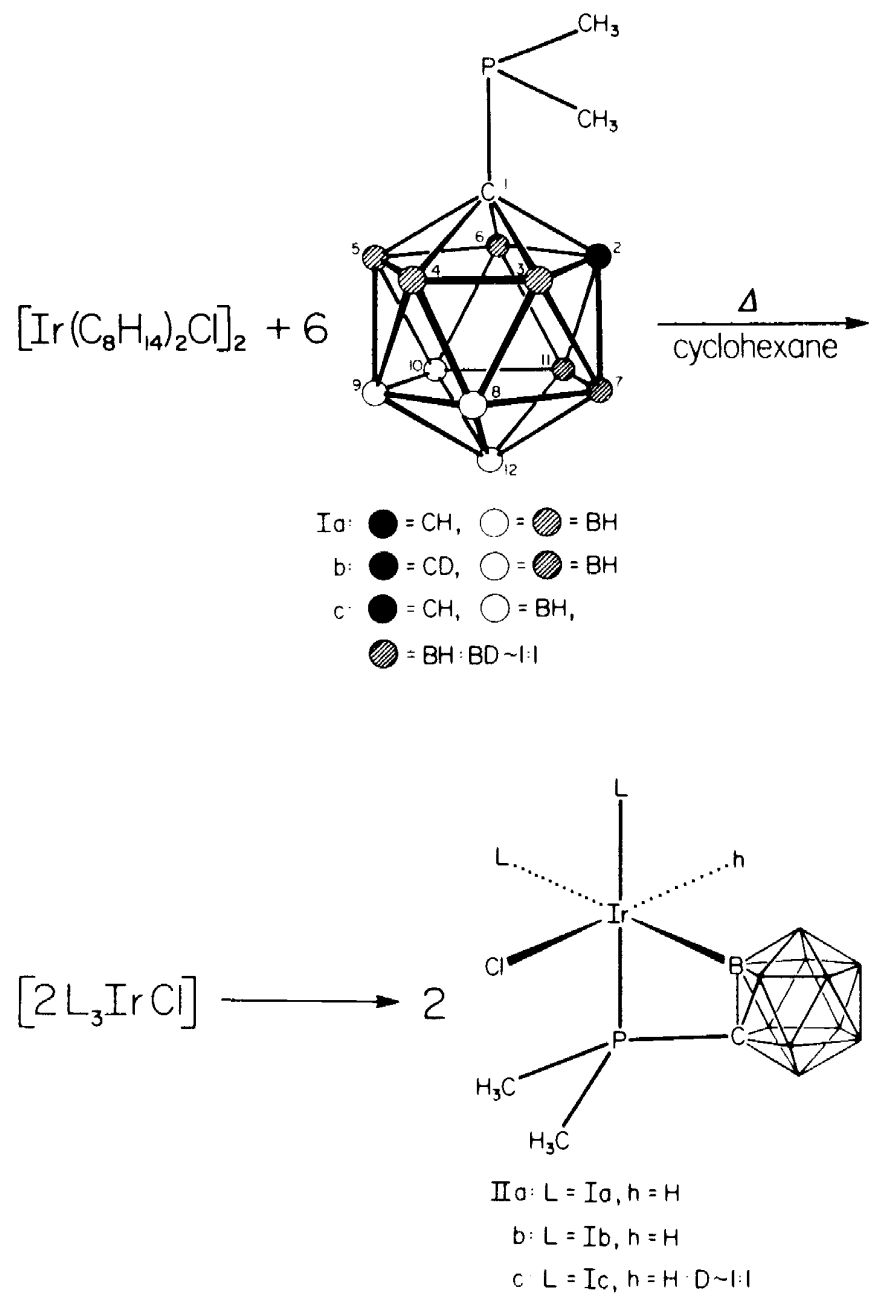

Figure 19. Oxidative addition to a polyhedral BH vertex.

shows significant catalytic behaviour for hydrogenation, olefin isomerization, and hydrosilylation, and is by at least an order of magnitude the best deuterium exchange catalyst for boron-hydrogen bonds we have found ${ }^{46,47}$. Table 1 outlines the results of our preliminary work with deuterium exchange. This is the first metallocarborane complex which has been shown to exhibit significant catalytic activity, but as it is also the first metallocarborane without accompanying carbonyl, cyclopentadienyl or carboranyl ligands, more efficient catalytic metallocarboranes may be discovered.

The presence of a carborane 'ligand' on a catalytically active metal may affect the course of reaction in several ways. The steric effects may be substantial, for the cage occupies a large portion of the catalytic surface of the 


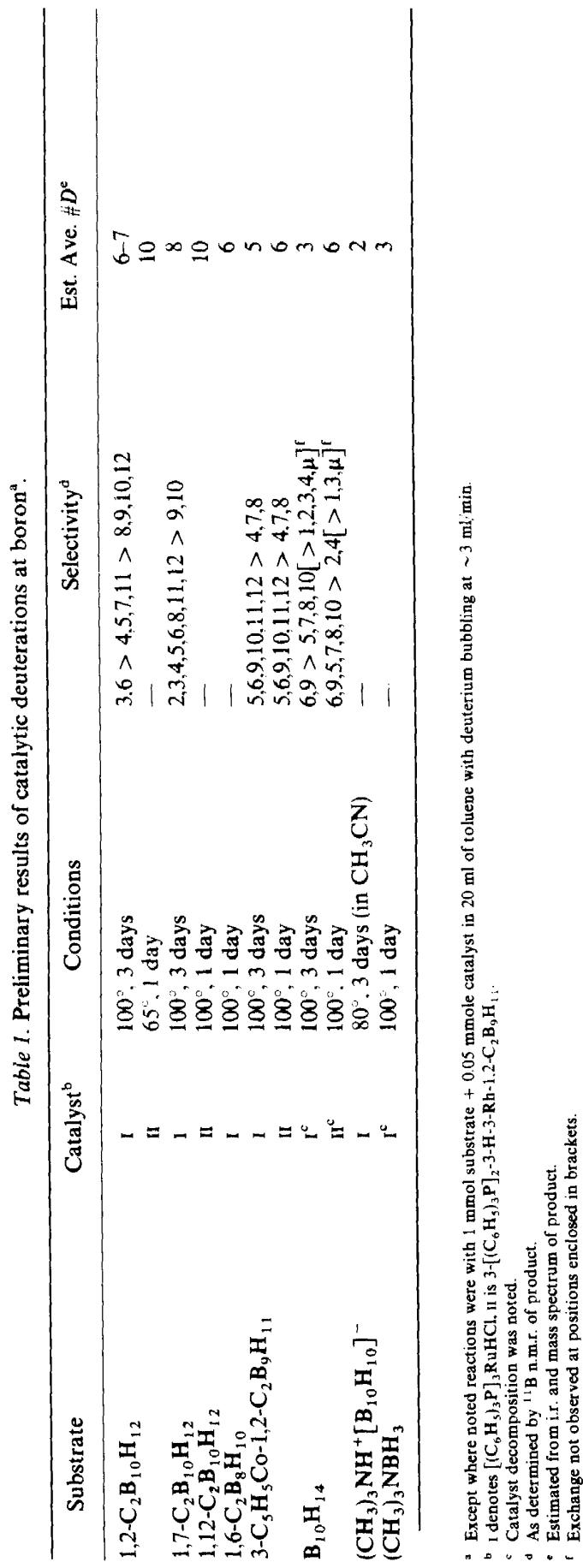


metal; however, in doing so, it may favourably influence the catalytic selectivity. Preliminary evidence indicates this to be true, and more detailed work is in progress. The electrophilicity of the ligand and its ability to adopt differing modes of coordination to a metal may also play an influence in the redox chemistry of the catalyst. All these various parameters are important to our understanding of catalytic behaviour and are being studied with the hope that some basic information of the effect of carboranyl ligands on catalytic behaviour may be derived.

\section{CONCLUSION}

In the relatively short period of ten years, metallocarborane chemistry has become an active and important field. In many respects we are attempting to compare metallocarborane with organometallic chemistries while simultaneously exploiting the unique nature of metallocarboranes. The latter effort will identify new areas for chemical adventure and innovation.

\section{REFERENCES}

1 M. F. Hawthorne. D. C. Young and P. A. Wegner, J. Amer. Chem. Soc. 87, 1818 (1965).

2 T. J. Kealy and P. L. Pauson. Nature. 168.1039 (1951)

3 W. Moffitt. J. Amer. Chem. Soc. 76, 3386 (1954).

${ }^{4}$ R. A. Wiesboeck and M. F. Hawthorne, J. Amer. Chem. Soc. 86, 1642 (1964).

M. F. Hawthorne, Endeavour. 25, 146 (1966).

M. F. Hawthorne and T. D. Andrews. J. Amer. Chem. Soc. 78. 2196 (1965).

M. F. Hawthorne and R. L. Pilling, J. Amer. Chem. Soc. 87, 3987 (1965).

${ }^{8}$ M. F. Hawthorne and T. D. Andrews, Chem. Commun. 443 (1965).

P. A. Wegner and M. F. Hawthorne, Chem. Commun. 861 (1966).

${ }^{10}$ L. F. Warren Jr and M. F. Hawthorne, J. Amer. Chem. Soc. 89. 470 (1967).

11 M. F. Hawthorne, D. C. Young, T. D. Andrews, D. V. Howe, R. L. Pilling A. D. Pitts. M. Reintjes. L. F. Warren Jr and P. A. Wegner, J. Amer. Chem. Soc. 90, 879 (1968).

12 M. F. Hawthorne and T. A. George, J. Amer. Chem. Soc. 89. 7114 (1967).

13 M. F. Hawthorne and A. D. Pitts, J. Amer. Chem. Soc. 89.7115 (1967)

${ }^{14}$ L. F. Warren Jr and M. F. Hawthorne, J. Amer. Chem. Soc. 90.4823 (1968).

15 R. J. Wilson, L. F. Warren Jr and M. F. Hawthorne. J. Amer. Chem. Soc. 91. 758 (1969).

16 G. B. Dunks and M. F. Hawthorne, J. Amer. Chem. Soc. 92.7213 (1970).

17 E. L. Hoel, C. E. Strouse and M. F. Hawthorne. Inorg. Chem. 13, 1388 (1974).

18 W. J. Evans, G. B. Dunks and M. F. Hawthorne, J. Amer. Chem. Soc. 95, 4565 (1973).

19 K. P. Callahan, C. E. Strouse, A. L. Sims and M. F. Hawthorne, Inorg. Chem. 13, 1397 (1974).

20 W. J. Evans and M. F. Hawthorne, J. Amer. Chem. Soc. 93, 3063 (1971).

21 W. J. Evans, Ph.D. Dissertation, University of California. Los Angeles (1973).

22 G. Evrard, J. A. Ricci Jr, I. Bernal, W. J. Evans, D. F. Dustin and M. F. Hawthorne, J. Chem. Soc., Chem. Commun. 234 (1974).

23 G. B. Dunks, M. M. McKown and M. F. Hawthorne, J. Amer. Chem. Soc. 93, 254 ( (1971).

24 D. F. Dustin, G. B. Dunks and M. F. Hawthorne, J. Amer. Chem. Soc. 95. 1109 (1973).

25 M. R. Churchill and B. G. DeBoer, J. Chem. Soc. Chem. Commun. 1326 (1972);

M. R. Churchill and B. G. DeBoer, Inorg. Chem. 13, 1411 (1974).

26 W. N. Lipscomb, Science, 153, 373 (1966).

27 W. J. Evans and M. F. Hawthorne. J. Chem. Soc.. Chem. Commun. 611 (1972).

${ }_{28}$ W. J. Evans and M. F. Hawthorne, Inorg. Chem. 13, 869 (1974).

${ }^{29}$ W. J. Evans and M. F. Hawthorne, J. Chem. Soc., Chem. Commun. 706 (1973).

30 W. J. Evans and M. F. Hawthorne, J. Chem. Soc., Chem. Commun. 37 (1974).

31 D. F. Dustin, W. J. Evans and M. F. Hawthorne, J. Chem. Soc., Chem. Commun. 805 (1973).

32 J. N. Francis and M. F. Hawthorne, J. Amer. Chem. Soc. 90, 1663 (1968);

J. N. Francis and M. F. Hawthorne, Inorg. Chem. 10. 863 (1971). 


\section{NEW CHEMISTRY OF METALLOCARBORANES AND METALLOBORANES}

${ }^{33}$ M. R. Churchill, A. H. Reis Jr, J. N. Francis and M. F. Hawthorne, J. Amer. Chem. Soc. 92, 4993 (1970).

${ }^{34}$ D. St. Clair, A. Zalkin and D. H. Templeton, Inorg. Chem. 8, 2080 (1969).

${ }^{35}$ C. J. Jones, J. N. Francis and M. F. Hawthorne, J. Chem. Soc, Chem. Commun. 900 (1972).

${ }^{36}$ C. J. Jones and M. F. Hawthorne, Inorg. Chem. 12, 608 (1973).

${ }^{37}$ C. J. Jones, J. N. Francis and M. F. Hawthorne, J. Amer. Chem. Soc. 94, 8391 (1972).

C. J. Jones. J. N. Francis and M. F. Hawthorne, J. Amer. Chem. Soc. 95, 7633 (1973).

; K. P. Callahan, F. Lo. C. E. Strouse, A. L. Sims and M. F. Hawthorne, Inorg. Chem., in press.

${ }^{34}$ D. F. Dustin and M. F. Hawthorne, J. Chem. Soc., Chem. Commun. 1329 (1972).

D. F. Dustin and M. F. Hawthorne, Inorg. Chem. 12, 1380 (1973).

40 K. P. Callahan, C. E. Strouse, A. L. Sims and M. F. Hawthorne, Inorg. Chem. 13, 1393 (1974).

41 D. F. Dustin and M. F. Hawthorne, J. Amer. Chem. Soc. 96, 3462 (1974).

42 C. G. Salentine and M. F. Hawthorne, J. Chem. Soc., Chem. Commun. 560 (1973).

${ }^{43}$ C. J. Jones, W. J. Evans and M. F. Hawthorne, J. Chem. Soc., Chem. Commun. 543 (1973).

${ }^{44}$ W. J. Evans and M. F. Hawthorne, J. Amer. Chem. Soc. 96, 301 (1974).

45 E. L. Hoel and M. F. Hawthorne, J. Amer. Chem. Soc. 95. 2712 (1973).

${ }^{46}$ E. L. Hoel and M. F. Hawthorne, J. Amer. Chem. Soc. 96, 4676 (1974).

47 T. E. Paxson and M. F. Hawthorne, J. Amer. Chem. Soc. 96, 4674 (1974). 